\title{
ARTIGOS
}

\section{AS INTERAÇÕES ENTRE DESIGN E GASTRONOMIA CONTEXTUALIZADAS ATRAVÉS DO MOVIMENTO SLOW FOOD: UMA ABORDAGEM INICIAL}

\section{THE INTERACTIONS BETWEEN DESIGN AND GASTRONOMY CONTEXTUALIZED THROUGH THE SLOW FOOD MOVEMENT: AN INITIAL APPROACH}

ÉDIPO JUNIOR BERTUOL |FSG

LUIZ ARMANDO CAPRA FILHO, M.SC. | FSG

\section{RESUMO}

Diante de um contexto que expõe rompimentos importantes na relação das pessoas com os alimentos, o design, de afinidade histórica com a gastronomia, vislumbra uma atuação mais ampla com essa ciência. Considerando esse cenário, o artigo tem como objetivo evidenciar as formas de contribuição do design para a alimentação e, especificamente, para o Slow Food, movimento mundialmente atuante em causas sustentáveis. A revisão bibliográfica realizada contextualizou as interações existentes entres as áreas e resultou na identificação de uma perspectiva de colaboração do design através da inovação social sistêmica, bem como a contribuição dos conceitos do Slow Food para o design, pelo viés da prática de uma abordagem lenta para uma economia sustentável.

PALAVRAS CHAVE: Design; Gastronomia; Movimento Slow Food; Sustentabilidade; Inovação Social.

\begin{abstract}
Faced with a context that exposes important disruptions in the relationship between people and food, design, of historical affinity with gastronomy, envisions a broader action with this science. Considering this scenario, the article aims to highlight the ways in which design contributes to food and, specifically, to Slow Food, a worldwide movement active in sustainable causes. The bibliographical review contextualized the interactions between the areas and resulted in the identification of a perspective of design collaboration through systemic social innovation, as well as the contribution of Slow Food concepts to design, through the practice of a slow approach to a sustainable economy.
\end{abstract}

KEY WORDS: Design; Gastronomy; Slow Food Movement; Sustainability; Social innovation. 


\section{INTRODUÇÃO}

Surgida como apenas um recurso para a sobrevivência humana, a alimentação passou a ser analisada, ao passar dos anos, por uma perspectiva multidisciplinar - a qual o design pertence - evidenciando sua importância em diversos contextos. $\mathrm{O}$ alimento, portanto, deixou de ser unicamente um insumo para a obtenção de energia e regulagem do organismo, e constitui-se como um fator influenciador nas relações sociais, econômicas e culturais, dentre outras, das pessoas.

Considerando o contexto de um mundo globalizado, onde as pessoas, de uma forma geral, têm de se adaptar ao desenvolvimento acelerado, às rotinas cansativas e à grande disseminação da informação, os hábitos alimentares vem sofrendo mudanças significativas. Dentre tantos aspectos, fica evidente "o processo de distanciamento humano em relação aos alimentos", como afirma Proença (2010, p.46). Neste cenário, ficam cada vez mais visíveis as novas relações de produção, transporte e consumo dos alimentos, bem como as suas consequências na sociedade.

Caminhando em oposição a esse cenário, surgem movimentos como o Slow Food que, em linhas gerais, buscam uma reconexão do ser humano com o alimento e, complementarmente, com o ato de consumi-lo. Atuante em defesa de um alimento bom, limpo e justo (PETRINI, 2015), a associação vem ganhando notoriedade e apoiadores em vários países, além de ser pauta nas discussões atuais sobre a gastronomia e a alimentação.

A oportunidade de estudar a gastronomia e, especificamente, o movimento Slow Food, sob os conceitos pertinentes do design - objeto principal do estudo - torna-se clara ao passo que ambas áreas do conhecimento se aproximam de forma natural e por, fundamentalmente, envolverem diversos aspectos das relações humanas. Para Montanari (2008, p. 183), "o sistema alimentar contém e transporta a cultura de quem a pratica, é depositário das tradições e da identidade de um grupo", e é justamente desta prerrogativa que, segundo Parreira (2014), surge a atual relação entre o design e o alimento e o consequente interesse dos designers na cultura da alimentação.

Outro importante vínculo a ser explorado para o desenvolvimento desse estudo é do design com a sustentabilidade, pois ambos, essencialmente, são orientados para o futuro (FRANZATO, 2017). Essa projeção do amanhã, sob a ótica do movimento Slow Food, requer uma cadeia produtiva integralmente sustentável que, além de fortalecer um cenário de alimentação saudável, tende a ampliar a distribuição de alimentos limpos e de maneira justa. Nesse contexto, é possível vislumbrar a participação de designers socialmente inseridos na construção de cenários verdadeiramente sustentáveis e com a alimentação como eixo central.

Evidenciar, de forma inicial, as formas de contribuição do design para a consolidação de movimentos gastronômicos como o Slow Food torna-se, portanto, o objetivo específico do presente artigo. Para tal, os estudos em gastronomia e design serão confrontados, visando a busca por similaridades nos métodos e a aplicação dos conceitos de uma área no contexto da outra. Com isso, pretende-se ampliar o diálogo e as interações entre as áreas, fomentando possíveis caminhos para a inovação e a sustentabilidade.

\section{METODOLOGIA}

Considerando o problema de pesquisa apresentado, optou-se por realizar uma pesquisa qualitativa, de natureza descritiva, e que tem por objetivo a "descrição de certo fenômeno, caracterizando sua ocorrência e relacionando-o com outros fatores" e com o contexto ao qual está inserido (CASARIN e CASARIN, 2012, p. 33). Além disso, a presente pesquisa classifica-se como exploratória, em virtude de ela ser "sobre um assunto já conhecido, visto sobre nova perspectiva" (CASARIN e CASARIN, 2012, p. 40), tendo como objetivo principal, segundo Gil (2002, p. 41), o "aprimoramento de ideias ou a descoberta de intuições". Apesar de flexível, geralmente a pesquisa exploratória assume a forma de pesquisa bibliográfica que, por sua vez, "é desenvolvida com base em material já elaborado, constituído principalmente de livros e artigos científicos" (GIL, 2002, p. 44). A principal vantagem da pesquisa bibliográfica, ainda segundo Gil (2002), é a possibilidade de investigação de uma gama muito mais ampla de fenômenos do que a pesquisa direta.

Tendo em vista a metodologia proposta e refletindo sobre o problema de pesquisa evidenciado, busca-se, nos parágrafos que seguem, elucidar as questões envolvidas nos âmbitos do design e da gastronomia. Estruturalmente, há, em um primeiro momento, um recorte histórico sobre a alimentação atual e seus reflexos na sociedade. Posteriormente, existe uma aproximação direta entre o design e a gastronomia, explanando as intervenções e os conceitos mais relevantes. Por fim, a relação entre estas áreas do conhecimento são estreitadas a fim de relacionar o design diretamente com o movimento Slow Food e, por consequência, evidenciar os benefícios mútuos surgidos deste vínculo.

\section{A ALIMENTAÇÃO NO MUNDO ATUAL}

Refletindo sobre o cenário contemporâneo, é possível perceber as fortes mudanças nas relações entre o ser humano e a alimentação. O modo de vida urbano, 
caracterizado pela falta de tempo, pelas relações estreitas com os recursos financeiros e pelo ritmo acelerado das mudanças, contribui diretamente para este fenômeno e geram novas demandas alimentares. Além disso, segundo Garcia (2003, p. 484) "as soluções são capitalizadas pela indústria e comércio", as quais acabam "apresentando alternativas adaptadas às condições urbanas e delineando novas modalidades no modo de comer".

Argumentando a favor deste contexto, a crescente alimentação fora de casa faz com que os restaurantes assumam novos papéis diante da sociedade e excedam seu significado primordial, retirado da etimologia, de um estabelecimento "restaurador de forças", conforme afirma Proença (2010). Neste cenário, portanto, a alimentação apresenta-se como coadjuvante de rotinas intensas.

Com a introdução da tecnologia na produção industrial e sistemas organizacionais, percebemos a inserção do método taylorista na cadeia de produção de alimentos. O método de preparo, a qualidade de ingredientes e a forma de produção tornam as refeições baratas e elas acabam por figurar como apenas intervalos entre as jornadas de trabalho (AKIYOSHI, 2012, p.33).

As refeições rápidas e com cardápios padronizados ganham amplitude e revelam-se como importantes influenciadores na economia e na saúde das pessoas de diferentes grupos sociais. De acordo com a Euromonitor (s.d., apud JACOBS e RICHTEL, 2017), de 2011 a 2016, o mercado do fast food registrou um crescimento mundial de $30 \%$ em todo o mundo. Além disso, conforme estudo da EAE Business School, em 2014 três países desenvolvidos e dois mercados emergentes formavam o grupo de nações que mais geraram receita provenientes do fast food. Em relação aos produtos industrializados, o crescimento nas vendas foi de $25 \%$ no mundo todo, no período de 2011 a 2016, segundo a Euromonitor (s.d., apud JACOBS e RICHTEL, 2017). Constata-se, a partir disso, que apesar dos contrastes econômicos e sociais, países ricos e em desenvolvimento apresentam comportamentos alimentares semelhantes, os quais contribuem diretamente para o aumento nas estatísticas de obesidade e diabetes, dentre outras doenças decorrentes da má alimentação.

A problematização em torno da alimentação atual é ampla e impacta outros aspectos para além da saúde pública. Em um estudo sobre a massificação dos alimentos industrializados nos países em desenvolvimento, Jacobs e Richtel (2017) revelam que o problema está diretamente ligado à economia, ao passo que, por exemplo, as multinacionais avançam nos países emergentes e alteram a agricultura local, fazendo com que os agricultores comecem a produzir insumos mais rentáveis, justamente aqueles que são a base de muitos produtos industrializados. No âmbito político, segundo os mesmos autores, a influência das grandes corporações nos governos de determinados países impede que as autoridades em saúde pública consigam taxar e criar leis para reduzir o impacto das bebidas açucaradas e dos alimentos processados. Entretanto, mesmo com os comprovados malefícios, há uma corrente de defesa aos alimentos industrializados, com o argumento de que eles "são essenciais para alimentar um mundo cada vez maior e mais urbanizado de pessoas", muitas das quais possuem "renda crescente e que demandam praticidade." (JACOBS e RICHTEL, 2017).

De uma forma geral, é legítimo afirmar que o ato de buscar, produzir, transportar, comunicar e, principalmente, consumir o alimento vem passando por modificações que impactam diretamente na relação entre o homem e a alimentação. Reflexo disso, segundo Proença (2010, p.43), é a "ruptura espacial e temporal da produção e do acesso" aos alimentos, causada, dentre outras, pela produção em larga escala, pela conservação longeva e pelas possibilidades globais de transporte e venda dos produtos. Para a autora, estes e outros aspectos compõem o cenário atual da alimentação e evidenciam, principalmente, o distanciamento das pessoas em relação aos alimentos.

Em contraposição a este cenário, surgem movimentos alimentares como o Slow Food que busca reconectar o ser humano com a mesa e as culturas alimentares, defendendo a biodiversidade, preservando e estimulando economias e produtos locais. O movimento propõe a valorização do alimento bom, limpo e justo para todos e se estabelece "difundindo a calma ao comer, o máximo proveito da refeição, considerando, além do conteúdo nutricional, os aspectos culturais e de prazer" (PROENÇA, 2010, p.46).

\section{O MOVIMENTO SLOW FOOD}

Ao afirmar que, diante desse panorama globalizado, o "alimento perdeu seus múltiplos e complexos valores, para se tornar uma commodity que tem sentido somente em função do seu preço", Carlo Petrini (2015, p.11), fundador do movimento Slow Food, revela uma situação preocupante, mas, ao mesmo tempo, justifica a existência de um movimento gastronômico com bases ideológicas tão bem estabelecidas. E são elas que, acima de tudo, questionam a conjuntura apresentada e fomentam a construção de uma estrutura em rede capaz de promover o alimento bom, limpo e justo. 
Traduzido literalmente, o termo Slow Food ganha o simples significado de "comida lenta", porém, ao passo que manifesta seus objetivos e propósitos, o movimento se estabelece como uma referência nos termos da alimentação atual. Por definição, o Slow Food é uma associação internacional, sem fins lucrativos, mantida por seus mais de 100.000 filiados em 160 países. Essencialmente, o movimento se sustenta na proposta de um alimento "bom, limpo e justo" e atua na defesa "dos alimentos tradicionais e sustentáveis de qualidade, dos ingredientes primários; pela conservação de métodos de cultivo e processamento e pela preservação da biodiversidade" (IRVING E CERIANI, 2013, p. 6). Além disso, o movimento acredita que "o alimento de qualidade é um direito fundamental" das pessoas, sendo delas a responsabilidade de "preservar o patrimônio de biodiversidade, cultura e saberes" (SLOW FOOD, 2016).

\subsection{O Slow Food como rede}

As mudanças que ocorrem no mundo nas últimas décadas estabelecem uma nova era que, segundo Castells (2005, p. 119) é intitulada de "informacional, global e em rede". Neste cenário, segundo o mesmo autor, a capacidade de aplicar e processar as informações baseadas torna-se um diferencial essencial dentro de uma rede global de interação. De forma complementar, Castells (2005, p.565) afirma que as "redes constituem a nova morfologia social das nossas sociedades e a difusão da lógica de redes modifica de forma substancial a operação e os resultados dos processos produtivos e de experiência, poder e cultura".

O Slow Food tem como viés principal o estabelecimento de uma rede que interligue produtores e coprodutores de alimentos, sustentando e disseminando a missão do movimento. A sua estrutura primordial é dividida em níveis internacional, nacional e local, conforme ilustra o Quadro 1.

\begin{tabular}{|l|l|}
\hline Nível & Atuação \\
\hline Internacional & $\begin{array}{l}\text { A sede internacional do Slow Food está localizada } \\
\text { na cidade de Bra, na Itália, local em que o movi- } \\
\text { mento nasceu. A associação é coordenada por um } \\
\text { Conselho Internacional, orientada por um Comitê } \\
\text { Executivo e presidida por seu fundador, Carlo Petrini. }\end{array}$ \\
\hline Nacional & $\begin{array}{l}\text { As estruturas em nível nacional têm autonomia } \\
\text { de decisão, porém respeitam as diretrizes do Slow } \\
\text { Food Internacional. Elas apoiam os Convívios, or- } \\
\text { ganizam eventos e são referência aos associados. }\end{array}$ \\
\hline Local & $\begin{array}{l}\text { Localmente, o Slow Food atua em grupos deno- } \\
\text { minados Convívios, os quais organizam reuniões, } \\
\text { eventos e coordenam as atividades nas cidades e } \\
\text { comunidades de todo o mundo. }\end{array}$ \\
\hline
\end{tabular}

Quadro 01 - Estrutura organizacional do Slow Food Fonte: Autor, com base no site institucional do Slow Food (2016).
Definida como a "rede das redes", a Terra Madre "é o projeto do Slow Food para criar uma rede internacional de produtores de alimentos e representantes de comunidades locais, cozinheiros, acadêmicos e jovens com a finalidade de estabelecer um sistema de produção de alimentos bom, limpo e justo" (IRVING E CERIANI, 2013, p.20). Diante de um cenário marcado pelo crescimento da agricultura industrializada, segundo os mesmos autores, o movimento apoia ativamente o "modelo local sustentável de pequena escala". A Terra Madre trabalha diretamente com os Convívios, que são "células locais e independentes, que trabalham para defender a cultura alimentar do território, divulgando e pondo em prática a filosofia e os objetivos da associação". Apesar de seguirem as diretrizes do movimento, os Convívios têm autonomia na atuação e realizam as iniciativas que atendem as exigências de cada contexto (SLOW FOOD, 2016).

A organização é aberta e qualquer pessoa pode tornar-se um associado. Assim que tornam parte da associação, os membros, de forma voluntária, participam ativamente das iniciativas nas suas comunidades promovendo eventos e campanhas e, consequentemente, "ajudando a mudar o sistema alimentar global" (SLOW FOOD, 2016). A diversidade é vista como um dos pontos mais fortes do movimento, principalmente por estarem envolvidos diferentes atores do amplo contexto da alimentação, desde agricultores a chefs de cozinha. Atuando de forma coletiva, esses profissionais têm, nos encontros promovidos pelo movimento, a "oportunidade de debater e compartilhar seus conhecimentos e experiências" (SLOW FOOD, 2016).

\section{GASTRONOMIA E DESIGN}

A alimentação, inegavelmente, tem ganhando notoriedade nas discussões atuais e deixou de ser vista apenas como uma atividade comum e corriqueira do ser humano. Esta expansão permitiu que o ato de se alimentar extrapolasse os limites das ciências culinárias e passasse a ser explorada por diferentes óticas. O design, notoriamente, inclui-se neste cenário e tem procurado relacionar os seus conceitos com o movimento gastronômico dos últimos anos. Esta relação tem reforçado a ideia de que o design transcende apenas a criação de objetos utilitários ou de comunicação, e se estabelece como a "capacidade de projetar artefatos de interface cultural" (MARTINS, 2010, p. 9).

Apesar de atuações distintas, o design e a alimentação revelam pontos de similaridade primordiais. Segundo Parreira (2014, p. 22), é possível perceber que "a gastronomia reflete a sociedade a partir das suas práticas, comportamentos e estilos de vida e, tal como o 
design, acomoda essas dimensões quando cria 'produtos' de consumo cotidiano". Soma-se a isso a percebida influência que ambas as áreas têm nas relações sociais, econômicas e culturais da sociedade, revelando uma aproximação importante e promissora.

O contexto do design e da alimentação, explanado através da Figura 1, evidencia perspectivas de atuação que envolvam as duas áreas. Por um lado, há relações tradicionalmente estabelecidas, como o vínculo entre o design e a comunicação dos alimentos, exemplificado pelo design de embalagens e de utensílios utilizados nas cozinhas. Porém, existem também vertentes em constante crescimento, com destaque para o Food Design, que atualmente é tema de um mestrado oferecido pela Scuola Politecnica di Design (SPD), localizada em Milão. Este interesse das instituições educacionais de design pela gastronomia, por sua vez, tem por objetivo a capacitação dos designers para a consolidação da inovação na indústria alimentícia (SPD, 2014).

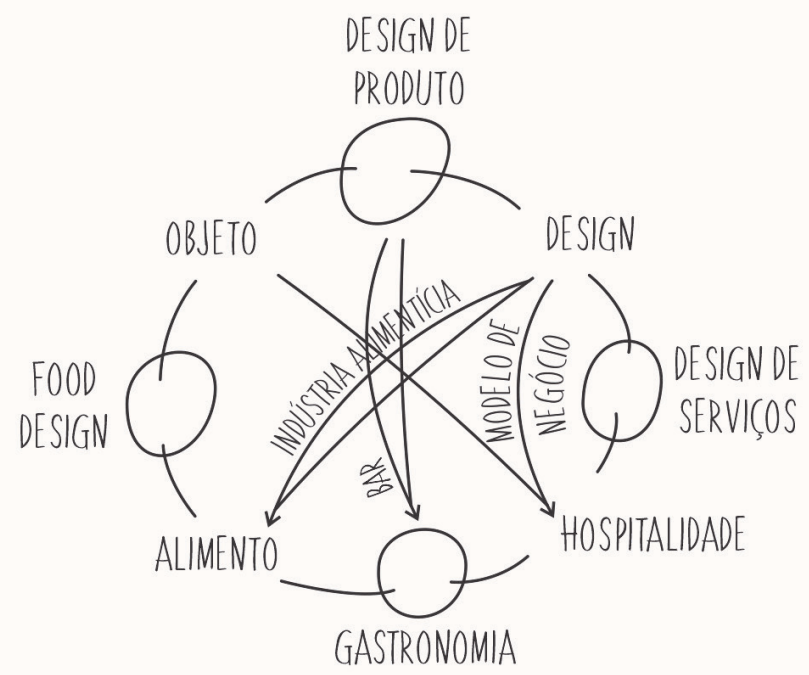

Figura 01 - Contexto da alimentação e do design Fonte: Adaptação do autor para SPD (2013)

A comida, historicamente, sempre serviu de suporte para a atuação dos designers que, por sua vez, segundo Parreira (2013, p.117), sempre "projetaram utensílios em torno da cozinha e da mesa, da ação de cozinhar e do ato de comer". No cenário atual, um dos reflexos da interação entre a gastronomia e o design é justamente a criação de objetos com foco na cozinha e na cultura alimentar, caracterizados pela diversidade de conceitos, variando da alta tecnologia ao rústico e o retorno ao básico. Soma-se a isso, por parte de designers e arquitetos, a reconsideração dos ingredientes, ferramentas e utensílios utilizados nos preparos culinários e a preocupação quanto a produção e o processamento dos alimentos, o que, especificamente, demanda o projeto de cozinhas e produtos sustentáveis e com baixo consumo de energia (BRIZZIO, 2011).

No entanto, de acordo com Parreira (2013, p.117), ao longo do tempo, "os designers pouco contribuíram para projetar os alimentos propriamente ditos", com exceção de projetos específicos, tratados como "pontuais e inconsequentes". Exemplo disso, a massa Marille (Figura 2), projetada pelo designer Giorgetto Giugiaro, não fez o sucesso esperado pelo fato da sua forma dificultar o cozimento uniforme (MARTELLOTTA, 2013). Em síntese, nesse caso específico, a dimensão estética do projeto foi mais valorizada do que a vertente funcional e essencial do alimento.
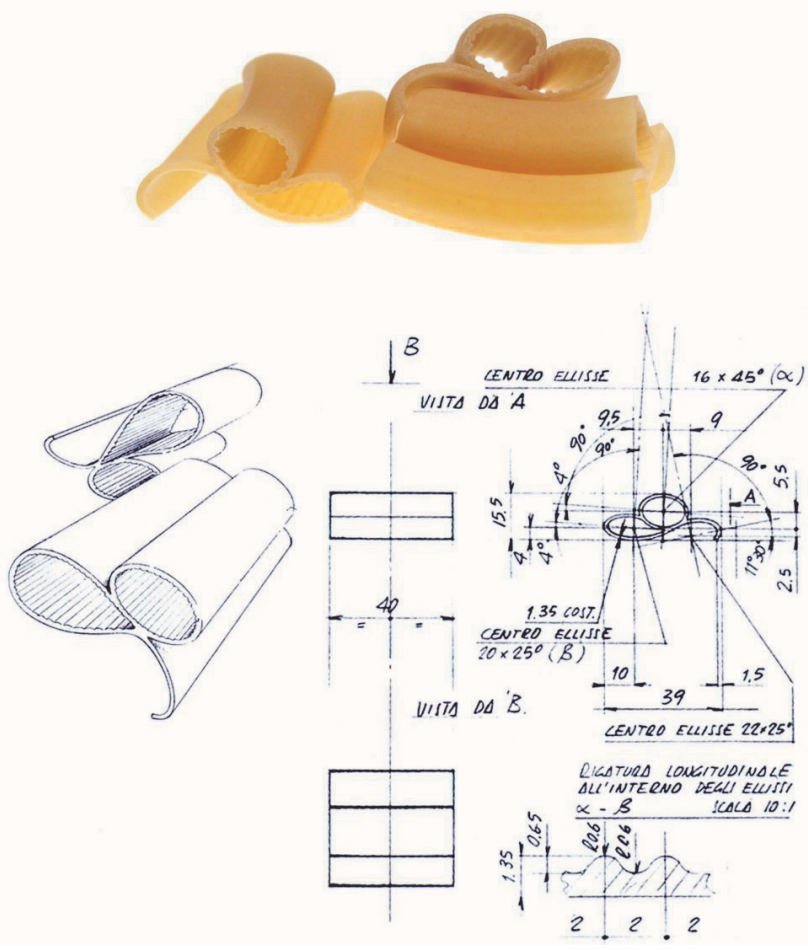

Figura 02 - Massa Marille Fonte: Italdesign (2010)

Há, porém, uma tendência atual em crescimento concentrada no design de alimentos que procura, além de aprimorar a apresentação dos alimentos, "levar os alimentos como um novo material para a produção artística em conjunto" (BRIZZIO, 2011). Dentro do presente contexto, evidencia-se o conceito do Food Design. Por definição, segundo a ADI - Associazione per II Disegno Industriale (2014):

Food Design é o projeto de atos alimentares (Food Facts), ou a atividade de elaboração dos processos mais eficazes para tornar correta e agradável a ação de experimentar uma substância comestível em um determinado contexto, 
ambiente ou circunstância de consumo. O Food Design leva em análise as razões pelas quais realizamos um ato alimentar para entender melhor projetá-lo e como atender de maneira adequada a exigência do usuário. O Food Design lida com produtos comestíveis, comunicação, embalagens, serviços e lugares relacionados com a venda e consumo de alimentos (ADI, 2014).

De forma complementar, Zampollo (2016, n.p) afirma que o Food Design é o "processo de design que leva à inovação em produtos, serviços ou sistemas de alimentação". Além disso, segundo Vogelzang (2008), esta disciplina tende a aprimorar a experiência da alimentação, bem como pode comunicar uma ideologia. Sobretudo, o profissional atuante nesta área do design deve "inovar e dar resposta às necessidades do usuário", método que tem êxito tanto no design quanto na gastronomia (MARTINS, 2010, p. 9).

\subsection{A relação do design com a gastronomia}

Substancial para a sobrevivência do homem, a alimentação deixou de ser vista apenas pelo seu valor nutricional. Passou, portanto, a ser explorada pelo seu viés cultural e pela sua capacidade de refletir o estilo de vida e a identidade de determinado grupo social, o diferenciando dos demais (MARTINS, 2010). Desta perspectiva, consolida-se um elo importante entre o design e a gastronomia, conforme aponta Catteral (1999):

Tal como o design que quando considerado superficialmente pode ser facilmente entendido mais estilo que conteúdo, o mesmo pode ser dito da alimentação. Uma verdadeira valorização do design abrange um entendimento da sua história, da sua capacidade de alterar a configuração do mundo e o modo como interagimos com ele, do progresso tecnológico e das conquistas criativas, da compreensão de nós mesmos e do ambiente. A alimentação representa quem somos, a nossa cultura e sociedade; alimenta os sentidos e as emoções; cria laços e mostra-nos o nosso lugar no mundo em relação às outras pessoas (CATTERALL, 1999, p. 33).

Historicamente, o design sempre contribuiu para a gastronomia, através da criação de utensílios ou artefatos de comunicação. Por outro lado, ele foi responsável pelo projeto de alimentos propriamente ditos, estes definidos por Parreira (2013, p. 117) como " pontuais e inconsequentes", tendo como exemplo a massa Marille criada por Giorgetto Giugiaro, já citada neste estudo. Giugiaro (em entrevista para Bernasconi, 2012) defende que, para projetos como esse, a forma é essencial, sendo muito importante pensar na funcionalidade do alimento no prato. Em contrapartida, de acordo com Parreira (2013, p. 117), "os alimentos são aceitos no cotidiano após uma sedimentação cultural de várias gerações", logo não devem ser impostos e ter seu foco apenas na representação formal.

O dinamismo e a complexidade do mundo atual, entretanto, fazem com que o design amplie seu foco projetual e evolua seu propósito, inicialmente centrado no projeto de produtos propriamente ditos, na direção de uma perspectiva sistêmica a qual, segundo Krucken (2009, p. 44), "caracteriza e estimula a atuação do design na contemporaneidade". Assim, ainda segundo a autora, "o principal desafio do design atualmente é desenvolver ou suportar o desenvolvimento de soluções para questões de alta complexidade, que exigem uma visão abrangente do projeto, envolvendo produtos, serviços e comunicação de forma conjunta e sustentável". Considerando a conjuntura da gastronomia e da alimentação, Parreira (2013) considera que:

Os desenvolvimentos, tendências e inovação na alimentação fazem do design um parceiro conveniente em grandes linhas programáticas como o ativismo social, os 'alimentos inteligentes' ou as soluções futuras baseadas em previsões demográficas, de padrões de consumo ou de capacidade de resposta da indústria alimen$\operatorname{tar}$ (PARREIRA, 2013, p.117).

Importante princípio do movimento Slow Food, a "abordagem multidisciplinar em relação à comida" (IRVING E CERIANI, 2013 , p. 5) surge como um fator que legitima a participação do design frente às circunstâncias envolvidas. Esta relação, por sua vez, se estabelece justamente pelo viés do ativismo social, oportunizando ao design a ampliação do diálogo e o estudo dos conceitos que naturalmente se relacionam.

\subsection{A contribuição do design para o Slow Food} Considerando o contexto apresentado, é possível elucidar a relação direta do design com o movimento Slow Food, encontro o qual, porém, não é recente. Em 6 de Outubro de 2006, o Slow Food Itália em colaboração com três instituições educacionais italianas organizou o seminário "Slow + Design", onde discutiram a "abordagem lenta da economia distribuída e a sensorialidade sustentável". Este evento buscou compreender o que se pode aprender com o modelo slow e como o design pode contribuir com o mesmo, seja dentro ou fora do mundo alimentar (SLOW FOOD, 2013).

Segundo o manifesto do seminário, uma "abordagem lenta" pode parecer simples, porém, nos dias atuais, a afirmação de que não é possível produzir e apreciar a 
qualidade se não houver algum tipo de desaceleração, tende a ser revolucionária. Além disso, essa "abordagem lenta" pode significar o cultivo de qualidade e a obtenção de resultados concretos, como a ligação entre produtos e produtores aos seus locais de produção e aos consumidores finais que, ao participarem da cadeia de produção, tornam-se coprodutores (CAPATTI et al, 2006). É possível, portanto, trazer à discussão o conceito de design voltado para a valorização do território, evidenciando as capacidades destes profissionais inseridos neste cenário. Conceitualmente, o uso do design nesse contexto significa "planejar ações que valorizem conjuntamente o capital territorial e o capital social, em uma perspectiva duradoura e sustentável em longo prazo" (KRUCKEN, 2009, p. 49). A inovação, por sua vez, é viabilizada pela união dos atores de uma comunidade local, como promovido pelo Slow Food e tem seu processo facilitado pelo design, que representa um importante coadjuvante no desenvolvimento econômico e sociocultural do território (KRUCKEN, 2009). Logo, nesse contexto, "as competências técnicas de design transformam-se em plataforma transdisciplinar que sustenta a convergência dos especialistas e dos demais atores que integram essa produtiva rede de colaboração" (FRANZATO, 2017, p. 102).

$O$ encontro desses dois temas tende a gerar contribuições mútuas ao passo que "a abordagem lenta pode abrir novas oportunidades de design, enquanto o design pode trazer ferramentas conceituais e operacionais úteis para a abordagem lenta" (CAPATTI et al, 2006, p.3). No entanto, nesta mesma perspectiva, é necessário considerar o risco de que essa relação do design com os alimentos limite-se à superficialidade das experiências alimentares e à espetacularização de um rico patrimônio histórico de técnicas, sabores, lugares e costumes sociais (CAPATTI et al, 2006). Em resumo:

$O$ risco é que a reunião de design com alimentos possa se desenvolver na direção oposta ao que a experiência do Slow Food, se interpretada corretamente, está propondo. Ao mesmo tempo, corremos o risco de perder a possibilidade de usar as lições fundamentais que Slow Food nos ensinou em outros campos de instrução, ou seja, o que chamamos de abordagem lenta (CAPATTI et al, 2006, p.3).

Por fim, o manifesto do seminário "Slow + Design" abre a perspectiva de um "novo design", ou seja, um projeto que "adota uma visão sistêmica, que analisa a complexidade das redes sociais, desenvolve uma capacidade de audição e inter-relações com a criatividade e o empreendedorismo" (CAPATTI et al, 2006, p.2). Como consequência, surge uma oportunidade de debate para elucidar os potenciais deste "novo design", bem como o mesmo pode orientar as transformações no modo de vida das pessoas e nas produções sustentáveis.

\subsubsection{O design e a inovação social}

Outrora ligado diretamente à concepção de produtos e serviços, o design, atualmente, visa estabelecer sua capacidade de promover o desenvolvimento social. Para Del Gaudio (2014, p.34), além de contribuir para a resolução de problemas sociais apresentados e constituir uma sociedade mais sustentável, esse movimento busca também manifestar que, "a estratégia de Design e as experiências criativas participativas e colaborativas" têm potencial para colaborar nesse processo. Constituem-se, desse modo, conceitos de um "Design com e não de Design para" (DEL GAUDIO, 2014, p.34) e do "design para o desenvolvimento" (BEST, 2012, p.17), aonde o design, segundo a autora, tem papel importante na forma como "vivemos, consumimos e funcionamos".

Analisando o contexto apresentado, portanto, constitui-se a perspectiva sistêmica do projeto de design e evidencia-se a importância do profissional dessa área. Identifica-se, com isso, o conceito da inovação social sistêmica onde os designers, segundo Manzini (2004, p.24), devem atuar como "facilitadores do processo de inovação". Ou seja, ainda que não atuem diretamente na realização do projeto, os designers têm papel fundamental na impulsão da inovação, apoiando a colaboração dos atores para a busca de um objetivo comum. Esses profissionais, por sua vez, devem ambicionar novas capacidades para além da criatividade, da capacidade de comunicação e do engajamento com a sustentabilidade, estas notáveis e já estabelecidas.

Adotar uma perspectiva ampla do projeto impli-
ca desenvolver competências relacionadas com
a interlocução, a análise simbólica, a escuta e a
ação em diferentes contextos, com a integração
de conhecimentos de diversas áreas e o desen-
volvimento de relações transversais na socieda-
de (KRUCKEN, 2009, p. 45).

O movimento Slow Food, à medida que engloba pessoas e suas inúmeras relações com os alimentos e com o ambiente, apresenta um contexto relevante para que essa contribuição do design seja efetiva. A busca por um alimento "bom, limpo e justo", ideologia central do movimento, nos esclarece em que frentes o Slow Food atua e de que formas busca consolidar-se como um ponto de oposição diante das conjunturas já discutidas. Ao desmembrar esse conceito, dentro do termo "Bom", Petrini $(2015$, p.38) ressalta a "atenção à qualidade organoléptica, ao prazer 
(pessoal ou partilhado, convivial), ao gosto compreendido também em termos culturais". Em relação ao vocábulo "Limpo", o mesmo autor aponta a relevância da sustentabilidade e da durabilidade de todos os processos, desde a semeadura que respeita a biodiversidade, até a distribuição ao consumidor final, a qual requer escolhas eficientes e que não gerem desperdícios. Por fim, em relação ao termo "Justo", Petrini (2015, p.38) acredita nas relações sem explorações, com remunerações suficientes aos trabalhadores do campo e, da mesma forma, com respeito aos recursos financeiros de quem compra, valorizando "a equidade, a solidariedade, a doação e o compartilhamento". Os aspectos apresentados, por sua vez, norteiam debates importantes na área do design e estabelecem relações diretas com a gastronomia.

As discussões acerca da sustentabilidade, por sua vez, estão cada vez mais presentes no contexto atuante do design. Apesar de considerar, de uma forma geral, o design como "parte do problema", Manzini (2008, p. 15) também adota uma visão que os designers podem de fato participar na resolução do problema, tendo em vista que, por essência, a razão de ser do design é melhorar a qualidade do mundo.

Nessa perspectiva, os designers podem ser parte da solução, justamente por serem atores sociais que, mais do que quaisquer outros, lidam com as interações cotidianas dos seres humanos com seus artefatos. São precisamente tais interações, junto com as expectativas de bem-estar a elas associadas, que devem necessariamente mudar durante a transição rumo à sustentabilidade (MANZINI, 2008, p. 16).

Contudo, a sustentabilidade, segundo Manzini (2008, p. 19), requer uma "descontinuidade sistêmica, ou seja, que se parta de uma sociedade que considera normal o "crescimento contínuo dos seus níveis de produção e consumo material" para uma que se desenvolva reduzindo estes níveis e melhore a qualidade de todo ambiente social e físico. De forma concisa, o autor acredita que para ser sustentável, "um sistema de produção, uso e consumo tem que ir ao encontro das demandas da sociedade por produtos e serviços sem perturbar os ciclos naturais e sem empobrecer o capital natural" (MANZINI, 2008, p.23). Essa reflexão engloba uma das principais causas do movimento Slow Food, que os alimentos sejam produzidos com "baixo impacto ambiental e respeitando o bem-estar animal" (SLOW FOOD, 2016). É reconhecível que, atualmente, os métodos mais comuns de produção de alimentos - como o plantio de espécies transgênicas e a utilização de agrotóxicos - são prejudicais à terra e aos consumidores, ficando evidente uma "agressão contra o gosto, biodiversidade, saúde dos seres humanos e animais, bem-estar e natureza" (IRVING E CERIANI, 2013, p.8).

Paralelamente a isso, há uma importante relação da sustentabilidade com o modo de vida das pessoas, principalmente o que se refere ao bem-estar. Manzini (2008) questiona o conceito já estabelecido do bem-estar baseado no produto, ou seja, o prazer das pessoas diretamente ligado à possibilidade de comprar cada vez mais artefatos. Em um contexto geral, o mesmo autor apresenta as tentativas de romper este ciclo de produção e consumismo constante. Em um primeiro momento, tentou-se aumentar a eficiência ambiental dos produtos o que, no entanto, ocasionou um efeito boomerang, e esses produtos ecoeficientes tornaram-se atrativos, aumentando sua demanda e seu consumo. A segunda tentativa de quebrar esse ciclo, foi chamado pelo autor como o "bem-estar vinculado ao acesso." Entretanto, a disposição de serviços e experiências, embora promissora, requeria grandes demandas de estruturas materiais que, no fim, acabavam somando-se aos produtos já existentes, e não os substituíam (MANZINI, 2008).

Diante dos resultados negativos e da projeção da insustentabilidade, Manzini (2008) propõe uma nova abordagem do "bem-estar ativo e relacionado ao contexto" e apresenta três hipóteses para fundamentar esse novo conceito: (1) a crise dos bens-comuns, (2) o desparecimento do tempo lento e contemplativo e (3) a difusão dos bens remediadores. Ao propormos uma relação destes assuntos com o movimento Slow Food, entretanto, é necessário dar um enfoque na segunda hipótese, que trata justamente do vínculo entre o tempo e as atividades humanas.

Em concordância com Manzini (2008, p. 48) "o tempo lento não é apenas o tempo no qual fazemos algo lentamente, mas também aquele no qual produzimos e/ ou apreciamos profundas qualidades". Com isso, há uma percepção por parte das pessoas que produzir e apreciar qualidades proporciona a elas uma ideia diferente de eficiência, pela disponibilidade do tempo necessário para realizar as atividades, bem como por constatar o alto grau de qualidade de produtos ou experiências a partir do desenvolvimento da sensibilidade e do conhecimento requerido. Historicamente importante na vida cotidiana, o tempo lento e contemplativo, nos tempos atuais, está desaparecendo devido a dois fenômenos complementares: a saturação e a aceleração, os quais têm interferido diretamente na relação das pessoas com os alimentos. Como já visto nesse estudo, a alimentação tem se tornado coadjuvante das 
rotinas aceleradas e, como consequência, as pessoas tem se afastado da mesa e os valores culturais e simbólicos dos alimentos estão sendo encobertos pelas refeições rápidas e industrializadas. Nesse contexto, constata-se que "a lentidão e o tempo lento não são valores em si, mas consequências da busca por algo que estamos perdendo na atual época do tempo veloz" (MANZINI, 2008, p. 49).

\section{CONSIDERAÇÕES FINAIS}

Com o propósito de contextualizar a relação do design com a alimentação, foi possível observar vínculos estabelecidos historicamente entre ambos. A título de exemplo, destaca-se a importância do design no desenvolvimento de embalagens e na criação de utensílios de cozinha, ações determinantes para o estabelecimento da afinidade da gastronomia com o design. Entretanto, observou-se também que determinadas perspectivas de atuação do designer neste cenário permanecem inertes ou com discussões extremamente recentes.

A fim de sustentar essas relações, buscou-se evidenciar, de forma primordial, a situação atual da gastronomia. A pesquisa, por sua vez, revelou um contexto onde a alimentação, antes vista como uma prática essencial para a rotina das pessoas, passou a basear-se em refeições rápidas e no consumo abundante de produtos industrializados, além de ter perdido seu valor simbólico. As consequências deste fenômeno refletem diretamente nos aspectos econômicos, sociais e culturais da sociedade. De forma mais agravante, entretanto, revelou-se um impacto na saúde das pessoas, legitimado pelo aumento das estatísticas de doenças relacionadas à má alimentação. Contundo, a partir deste estudo, também foi possível estabelecer a importância de movimentos como o Slow Food, organização mundialmente atuante, principalmente, na defesa da biodiversidade e na proposta de uma alimentação saudável baseada em insumos limpos que constituam uma cadeia produtiva justa para todos.

Partindo desse cenário, foi possível identificar que o conceito da inovação social sistêmica, onde o designer tem o papel de facilitador de processo de inovação, apresentou-se como uma forma em potencial para colaborar na atuação do movimento Slow Food. Diante disso, também foi possível identificar a importância do conceito da sustentabilidade e suas diferentes implicações na atuação do profissional de design. Dessa forma, a utilização de ferramentas criativas para o desenvolvimento de um ambiente de colaboração e empreendedorismo sustentável manifestou-se como um método para concretizar a concepção de designers socialmente responsáveis. Todavia, constatou-se também uma contribuição mútua nessa relação, ao passo que se identificou um panorama de aprendizado por parte do design diante da "abordagem lenta" proposta pelo movimento Slow Food.

Com isso, ao fim da pesquisa, foi possível evidenciar possibilidades de aprofundamento no estudo das relações do design com a gastronomia e, de forma específica, com os aspectos sociais e culturais envolvidos. Estas relações, por sua vez, tendem a gerar pesquisas mais amplas, que apresentem diferentes ferramentas e fortaleçam o vínculo, de potencial reconhecido, entre essas disciplinas.

\section{REFERÊNCIAS}

ADI - Associazione per il Disegno Industriale. Food Design Manifesto. Disponível em: <https://bit.ly/3i9fmzB>. Acesso em: 26 jul. 2017.

AKIYOSHI, R. Y. Design de triggers emocionais para experiências gastronômicas. Porto Alegre: UNISINOS, 2012. Dissertação (Mestrado em Design) Unidade Acadêmica de Pós-Graduação, Universidade do Vale do Rio dos Sinos, 2012.

BERNASCONI, S. Quanto tempo mi costò progettare le Marille. La Repubblica. Disponível em: <https://bit. ly/2VsHCU3>. Acesso em: 20 ago. 2017.

BEST, K. Fundamentos de gestão do design. Tradução de André de Godoy Vieira. Porto Alegre: Bookman, 2012.

BRIZZIO, P. Food for Thought: Can Design in Food Reach New Potentials? The Huffington Post. Disponível em: <https://bit.ly/2VsMOqV>. Acesso em: 25 fev. 2018. CAPATTI, A. et al. Slow + Design. Manifesto + Abstracts. Disponível em: <https://bit.ly/38a15hm>. Acesso em: 10 jan. 2018.

CASARIN, H. C. S.; CASARIN, S. J. Pesquisa científica: da teoria à prática. Curitiba: InterSaberes, 2012.

CASTELLS, M. A sociedade em rede. 8 ed. Tradução de Roneide Venancio Majer. São Paulo: Paz e Terra, 2005.

CATTERALL, C. Food: design and culture. Londres: Laurence King Publishing, 1999.

DEL GAUDIO, C. Design Participativo e Inovação Social: a influência dos fatores contextuais. Rio de Janeiro: PUC-Rio, 2014. Tese (Doutorado em Design) Programa de Pós-Graduação em Design, Pontifícia Universidade Católica do Rio de Janeiro, 2014.

EAE Business School. Fast food consumption in Spain will rise by $\mathbf{5 0} \%$ over the next five years. Disponível em: <https://bit.ly/2Abqs5U>. Acesso em: 25 fev. 2018. 
FRANZATO, Carlo; Redes de projeto: formas de organização do design contemporâneo em direção à sustentabilidade, p. 99-110. In: OLIVEIRA, A. J. de; FRANZATO, C.; GAUDIO, C. D. (orgs.). Ecovisões projetuais: pesquisas em design e sustentabilidade no Brasil. São Paulo: Blucher, 2017.

GARCIA, Rosa Wanda Diez. Reflexos da globalização na cultura alimentar: considerações sobre as mudanças na alimentação urbana. Revista de Nutrição, v.16, n.4, p. 483-492, 2003.

GIL, A. C. Como elaborar projetos de pesquisa. 4 ed. São Paulo: Atlas, 2002.

IRVING, J.; CERIANI, S. Manual do Slow Food. Disponível em: <https://bit.ly/3dGwJ7i>. Acesso em: 15 set. 2017.

ITALDESIGN. Project Marille. Disponível em: <https:// bit.ly/3dHoB6C>. Acesso em: 19 set. 2017.

JACOBS, A.; RICHTEL, M. Como a Grande Indústria viciou o Brasil em Junk Food. The New York Times. Disponível em: <https://nyti.ms/2Vtbfoe>. Acesso em: 20 fev. 2018.

KRUCKEN, L. Design e território: valorização de identidades e produtos locais. São Paulo: Studio Nobel, 2009.
Faculdade de Belas-Artes, Universidade de Lisboa, 2014.

PETRINI, C. Comida e liberdade: Slow Food - histórias de gastronomia para a libertação. Tradução de Renata Lucia Bottini. São Paulo: Editora Senac São Paulo, 2015. PROENÇA, R. P. C. Alimentação e globalização: algumas reflexões. Ciência e Cultura, v. 62, n. 4, p. 43-47, 2010.

SLOW FOOD (Brasil). Sobre Nós. Disponível em: <https://bit.ly/2VtFIT5>. Acesso em: 23 jul. 2017.

SLOW FOOD. Rede de Associados. Disponível em: <https://bit.ly/3icMw16>. Acesso em: 23 jul. 2017.

SLOW FOOD. Slow + Design. Disponível em: <https:// bit.ly/3dIM4nM>. Acesso em: 25 fev. 2018.

SPD - SCUOLA POLITECNICA DI DESIGN. Master Program in Food Design and Innovation. Disponível em: <https://bit.ly/31rFzDw>. Acesso em: 20 jan. 2018. VOGELZANG, M. Eat Love. Amsterdam: Bis Publishers, 2008.

ZAMPOLLO, F. What is Food Design? The complete overview of all Food Design sub-disciplines and how they merge. Disponível em: <https://bit.ly/ 3dl5n0J>. Acesso em: 20 jan. 2018. 


\section{AUTORES}

ORCID: https://orcid.org/0000-0001-7424-9122

ÉDIPO JUNIOR BERTUOL | Centro Universitário da Serra Gaúcha | Curso: Especialização em Gestão do Design e Inovação | Caxias do Sul, RS, Brasil. | Correspondência para: R. João Buratti, 374 - B. Rio Branco - Caxias do Sul - RS - Cep: 95.099-250 | e-mail: edipobertuol@gmail.com

ORCID: https://orcid.org/0000-0001-6554-3717

LUIZ ARMANDO CAPRA FILHO, M.Sc. | Professor mestre em Memória Social e Bens Culturais | Unilasalle - Mestrado em Memória Social e Bens Culturais | Canoas, RS, Brasil. |Correspondência para: Av. Panamericana, 150 / 237 Porto Alegre - RS - Cep: 91.050-000 | e-mail: la_capra@ hotmail.com

\section{COMO CITAR ESTE ARTIGO}

BERTUOL, Édipo Junior; FILHO, Luiz Armando Capra. As Interações entre Design e Gastronomia Contextualizadas através do Movimento Slow Food. MIX Sustentável, [S.I.], v. 6, n. 4, p. 73-84, ago. 2020. ISSN 24473073. Disponível em:<http://www. nexos.ufsc.br/index.php/mixsustentavel>. Acesso em: dia mês. ano. doi:https://doi.org/10.29183/2447-3073. MIX2020.v6.n4.73-84. 
